\title{
Detection of estrogenic hormone $17 \beta$-estradiol in soil samples by a recombinant yeast bioassay and supercritical fluid extraction
}

\author{
Jae-Han Shim ${ }^{1 * *}$, Mi Ra Kim", Edward Topp ${ }^{2)}$, Jeong-Heui Choi ${ }^{11}$, and Iqbal Rouf Mamun ${ }^{1,3)}$ \\ ${ }^{1)}$ Division of Applied Bioscience and Biotechnology, Chonnam National University, Gwangju, Republic of Korea \\ ${ }^{2)}$ Agriculture and Agri-Food Canada, ON, Canada \\ ${ }^{3)}$ Department of Chemistry, University of Dhaka, Dhaka-1000, Bangladesh
}

(Received July 25, 2008, Accepted December 16, 2008)

\begin{abstract}
Recombinant yeast estrogenicity (YES) assay was used as a bioanalytical tool in order to screen $17 \beta$-estradiol in the soil samples collected from different sites of South Korea. Solvent extraction and supercritical fluid extraction (SFE) methods were compared for the extraction of the estradiol from the soils. Most high detection of the estradiol based on YES assay was observed in the soils extracted with methanol. Different types of estrogenic homones including $17 \beta$-estradiol were suggested to be possibly exiting in the soils, since the methanol extracts of the soils showed an estrogenic activity that was not observed in the hexane extracts of the soil. SFE extracts showed estrogenic activity in some of the samples but methanol extract showed best activity.
\end{abstract}

Key Words: $17 \beta$-Estradiol, Supercritical fluid extraction (SFE), Soil, Recombinant yeast estrogenicity (YES) assay

\section{INTRODUCTION}

Many chemical compounds of natural or anthropogenic origin are suspected to be endocrine disruptors. Being a sensitive topic 'endocrine disruption' has become an important agenda of many expert's groups, steering committees and panels of governmental organization throughout the world. The messengers of the endocrine system are hormones which influence several essential regulatory, growth, developmental and homeostatic mechanisms of the organism, such as reproduction, maintenance of normal levels of glucose or ions in the blood, blood pressure, general metabolism and other muscle or nervous system functions. So, the balance of hormones in the organism is essential in order to prevent functional disorders. ${ }^{1)}$

$17 \beta$-Estradiol is a sex hormone represents the major

*Corresponding author:

Tel: +82-62-530-2135 Fax: +82-62-530-0219

E-mail: jhshim@jnu.ac.kr estrogen in humans and is one of the endocrine disrupting chemicals (EDCs) was identified as an estrogenic substance in Saccharomyces cerevisiae, which possess a high-affinity estrogen binding protein. ${ }^{2)}$ The presence of EDCs in the environment has become a major concern due to their harmful effects on reproduction, growth and development in certain species of wild-life, and increases in the human reproductive disorders and some cancers. ${ }^{3-7)}$ Widespread sexual abnormalities in wild populations of riverine fish throughout the United Kingdom have been described due to exposure to the estrogenic chemicals. ${ }^{8)} 17 \beta$ -Estradiol and its metabolite estrone have been found to be bioactive even at remarkably low environmental concentrations. Vitellogenin is a protein synthesized by the liver of oviparous fish in response to estradiol stimulation; it is then conveyed by the blood to the ovary, where it is sequestered by oocytes to form the yolk. Thus, the presence of vitellogenin in the plasma is indicative of estrogenic stimulation of the liver. 
Pronounced increase in the plasma vitellogenin concentration in fish was observed by Purdom et al with concentrations as low as $1 \mathrm{ng} / \mathrm{l}$ of ethynylestradiol in a laboratory study. ${ }^{9)}$

The presence of natural and xenoestrogenic compounds in environmental samples have been well documented. Peterson $e t a l^{4)}$ reported the presence of $17 \beta$-estradiol in five spring water samples at a concentration ranged from 6 to $66 \mathrm{ng} / \mathrm{l}$ collected from mantled karst area of northwest Arkanas. 17ß -Estradiol and its common metabolite estrone along with a synthetic analog 17 a-ethynylestradiol were isolated from the sewage-treatment works effluent and surface water in United Kingdom ${ }^{10,11)}$ and in lake and drinking water in Israel $^{12)}$ although the concentrations were unlikely to possess a significant risk to human health. Recently, Kim et $a l^{13)}$ reported the detection of estrone in surface water and wastewater treatment plant effluents in South Korea at concentrations between 1.5 and $5.0 \mathrm{ng} / \mathrm{L}$. Isolation of these compounds in soil and sediment samples have also been reported in the field-monitoring studies linked to the application of bio-solids like manure or sewage sludge. Finlay-Moore et al measured estradiol and testosterone concentrations in soil and runoff water from grazed and ungrazed grasslands amended with broiler litter. ${ }^{14)} 17 \quad \alpha$ - and $\beta$-estradiol as the degraded products of estrogens were also found in dairy manure waste solid (press-cake) by Raman et $a l^{15)}$ Significant sorption probabilities of parent and primary transformation products of estrogens and testosterones in soil and sediment have also been reported. ${ }^{16,17)}$

Detection of estrogenic compounds at various significant concentrations in the run-off, soil and sediment samples has remarked the animal wastes as a potential source for $17 \beta$-estradiol and its metabolites. Agriculture land can potentially receive these materials when treated with animal manure as a source of fertilizer for the plants and crops. Assessment of the extent of soil contamination by EDCs is one of the essential steps which would help the environment to avoid the exposure to these chemicals. Instrumental methodologies have been well reported for tracking the estradiol in soils. ${ }^{7,1819)}$ However, these methods are based on vigorous solvent extractions and tedious sample cleanup procedures. To identify and quantify the estradiols present in the environmental samples at a remarkably low concentration might also require some additional steps. Therefore, development of more sensitive and simple methods for better monitoring of estradiols present in the environment is a great concern of the environmental scientists.

In this study, a recombinant yeast estrogenicity (YES) assay developed by Routledge and Stumpter has been used as a bioanalytical tool to detect these estradiols. ${ }^{20)}$ The YES method is sensitive and selective as it is based on hormone-receptor binding biochemistry. To date, however, little studies on the application of this bioanalytical approach for detecting estradiols in soil samples have been reported. This might be due to the lack of proper extraction method of estradiol from soils. Thus, we are reporting the application of YES assay to detect $17 \beta$-estradiol in soils by Supercritical fluid Extraction (SFE) method comparing with a simultaneous solvent extraction method.

\section{MATERIALS AND METHODS}

\section{Sample collection}

Seven soil samples from different locations of Korea were collected. Two samples (Sample-1 \& 2) were collected from Yeosu industrial area, Sample-3 was from the area of Yeocheon public corporation which produces petrochemicals and refined oil, Sample-4 from agricultural field of Chonnam National University around the animal house, Sample- 5 was collected from a paddy field located in Jangseong county and Sample-6 \& 7 were from Seosan area located at the middle of South Korea.

\section{Solvent extraction}

A $6.0 \mathrm{~g}$ of representative soil sample (e.g. Sample-1) was suspended into $30 \mathrm{ml}$ of $n$-hexane and was sonicated for $90 \mathrm{~min}$ using an ultrasonic bath at room temperature. The mixture was centrifuged for $5 \mathrm{~min}$ at $15,000 \mathrm{rpm}$ and the $n$-hexane soluble part was separated from the soil by decantation. The residue was further extracted with $30 \mathrm{ml}$ of methanol following the same procedure. Both the hexane (H-1) and methanol (M-1) extracts were separated, centrifuged and evaporated to a final volume of $5 \mathrm{ml}$ using rotary evaporator. All other samples (Sample 2-7) were extracted in a similar manner and the $n$-hexane and 
methanol extracts were labeled accordingly.

\section{Super-critical fluid Extraction (SFE) procedure}

Two grams of soil sample was loaded into the vessels for SFE. Jasco Model PU980 dual pump (Tokeyo, Japan), one for pure $\mathrm{CO}_{2}$ and the other for methanol were used for the SFE procedure. The pumps were connected with a column oven, a back-pressure regulator and a $10-\mathrm{ml}$ high pressure vessel. The vessel was pressurized with $\mathrm{CO}_{2}$ to 300 bars at a temperature of $80^{\circ} \mathrm{C}$ and the soluble compounds were then flushed from the vessel by a 20 min extraction process at a flow rate of $2.6 \mathrm{ml} / \mathrm{min}$. The extract was vented into a tube containing $10 \%$ methanol to trap the compounds while the $\mathrm{CO}_{2}$ was bubbled off. The extract was filtered through a $0.45 \mu \mathrm{m}$ membrane filter and the compounds were identified and confirmed using a GC/MS.

\section{The recombinant yeast estrogenicity (YES) assay}

The recombinant yeast estrogenicity assay was carried out following the method described by Routledge \& Sumpter ${ }^{20)}$ with slight modification. In this system, the human estrogen receptor is expressed in recombinant yeast. When an active ligand binds to the receptor, the receptor gene is expressed in the yeast and produces $\beta$-galactosidase, which metabolizes a chromogenic substrate into a red product that can be quantified by absorbance at $540 \mathrm{~nm} \cdot{ }^{21)}$

\section{Preparation of medium components}

Different medium components were prepared by following the instructions given by Routledge and Sumpter. ${ }^{20)}$

Minimal medium ( $\mathrm{pH}$ 7.1) includes following compounds in g per liter: L-leucine (0.05), L-histidine $(0.05)$, adenine $(0.05)$, L-arginine-HCL $(0.02)$, L-methionine (0.02), L-tyrosine (0.03), L-isoleucine (0.03), L-lysine-HCl (0.03), L-phenylalanine (0.025), L-glutamic acid (0.1), L-valine (0.15), L-serine (0.375) along with anhydrous $\mathrm{KH}_{2} \mathrm{PO}_{4}$ (monobasic, 13.61), $\left(\mathrm{NH}_{4}\right)_{2} \mathrm{SO}_{4}$ (1.98), $\mathrm{MgSO}_{4}$ (0.2), $\mathrm{KOH}$ pellets (4.2) and aq. Solution of $\mathrm{Fe}_{2}\left(\mathrm{SO}_{4}\right)_{3}$ $(1 \mathrm{ml}, 40 \mathrm{mg} / 50 \mathrm{ml})$. The mixture was stirred and warmed with partial volume of water in order to go into solution and then the volume $(1 l)$ was adjusted with ultrapure water. The medium was sterilized at $121^{\circ} \mathrm{C}$ for $10 \mathrm{~min}$ and cooled down with shaking.
Vitamin solution was prepared by mixing $8.0 \mathrm{mg}$ of thiamine hydrochloride, pyridoxine and D-pantothenic acid (Na salt), $40 \mathrm{mg}$ of myo-inositol and $20 \mathrm{ml}(2 \mathrm{mg}$ $/ 100 \mathrm{ml}$ water) of biotin solution. The mixture was diluted to $200 \mathrm{ml}$ by ultrapure water and filtered through $0.2 \mu \mathrm{m}$ pore size sterile syringe filters and stored at $4^{\circ} \mathrm{C}$ in sterile vials.

Growth medium (about $50 \mathrm{ml}$ ) was prepared by adding $5 \mathrm{ml}$ glucose solution, $0.5 \mathrm{ml}$ vitamin solution, $1.25 \mathrm{ml} \mathrm{L}$-aspartic acid solution, $0.4 \mathrm{ml}$ L-threonine solution and $125 \mu l$ copper (II) sulfate solution to $45 \mathrm{ml}$ minimal medium in a sterile conical flask. A $50 \mathrm{ml}$ of the growth medium was placed in a sterile flask and $25 \mu l$ of concentrated yeast stock was added to it. The content was then incubated at $28^{\circ} \mathrm{C}$ for about $19 \mathrm{~h}$ on a mechanical shaker until an absorbance at $640 \mathrm{~nm}$ of 1.0 was reached.

Assay medium (about $50 \mathrm{ml}$ ) was prepared by adding glucose solution $(5 \mathrm{ml})$, L-aspartic solution $(1.25 \mathrm{ml})$, vitamin solution $(0.5 \mathrm{ml})$, L-threonine solution $(0.4 \mathrm{ml})$, copper (II) sulfate solution (125 $\mu l)$, CPRG (chromogen chlorophenol red-ß-D-galactopyranoside; $0.5 \mathrm{ml}$ ), yeast culture ( $2 \mathrm{ml} ; \mathrm{A} 640=1)$ to $45 \mathrm{ml}$ of minimal medium.

\section{Preparation of yeast stock}

The Glaxo yeast starin C249 was stored as a $10 \mathrm{x}$ concentrated stock culture in $0.25 \mathrm{ml}$ aliquots in 2-ml sterile cryovials. The yeast stock was prepared in three consecutive days. In the day 1, $50 \mathrm{ml}$ of growth medium was placed in a sterile flask and $25 \mu l$ of concentrated yeast stock was added. The content was incubated for about $19 \mathrm{~h}$ at $28^{\circ} \mathrm{C}$ in order to achieve $\mathrm{A} 640=1$. In the second day, $50 \mathrm{ml}$ of minimal medium was placed into two sterile flasks and $1.0 \mathrm{ml}$ of yeast from $24 \mathrm{~h}$ culture (day 1 ) was added to each flask. The mixture was then incubated for about $24 \mathrm{~h}$ at $28^{\circ} \mathrm{C}$ until $\mathrm{A} 640=1$ was achieved. In the day 3, each $24 \mathrm{~h}$ culture was transferred to two sterile centrifuge tubes $(25 \mathrm{ml})$ and centrifuged at $4^{\circ} \mathrm{C}$ for $10 \mathrm{~min}$ at 2000 g. The supernatant was decanted and each culture was re-suspended in $5 \mathrm{ml}$ of minimal medium containing $15 \%$ glycerol and the two cultures were pooled and stored at $-70^{\circ} \mathrm{C}$ freezer.

\section{Preparation of standard solution}

A stock solution of $0.01 \mathrm{M} 17 \beta$-estradiol was prepared in absolute ethanol (anhydrous). A medium 
stock solution of $0.2 \mathrm{mM}$ was prepared by diluting $20 \mu \mathrm{l}$ of stock solution to $1.0 \mathrm{ml}$ by ethanol and a working standard solution of $2000 \mathrm{nM}$ was prepared by diluting $10 \mu \mathrm{l}$ of $0.2 \mathrm{mM}$ medium stock solution to $1.0 \mathrm{ml}$ with the same solvent. All the stock solutions were stored in dark at $4^{\circ} \mathrm{C}$ when they were not in use.

All serial dilutions were carried out in ethanol from the working stock solution in order to achieve final concentrations of 100 to $0.003 \mu \mathrm{M}$ in the microtiter plate wells.

\section{Assay Procedure}

The yeast assay was carried out in a type II laminar air flow cabinet to minimize aerosol formation. Representative dried extracts were re-suspended in $1 \mathrm{ml}$ of absolute ethanol and was serially diluted with the same solvent. A $10-\mu l$ aliquots of each concentration were then transferred to a 96-well optically flat microtiter plate and was allowed to evaporate to dryness. Figure 1 shows the picture of three sets of microtiter plates for hexane, methanol and SFE extracts, each set contain three plates (Plate 1, 2 \& 3). First two rows represents standard estradiol and each pair of rows downwards represent sample extracts e.g. for hexane extract, H-I, H-2, up to H-7. Each well of the assay plates were introduced to $0.5 \mathrm{mM}$ estradiol for anti-estrogenicity and allowed it to be dried before adding the test dilutions. Aliquot $(200 \mu l)$ of assay medium was then introduced to each well. The plates were sealed with autoclave tape and shaken vigorously for $5 \mathrm{~min}$ on a titer plate shaker. After shaking, the plate was covered by foil and incubated at $30^{\circ} \mathrm{C}$ for 3 days. After incubation, the color development of the medium was checked periodically at an absorbance of 550 and $630 \mathrm{~nm}$ using a microtiter plate reader.

\section{Gas chromatography-Mass spectrometry identification}

The presence of estradiol in the soil samples was confirmed by GC-MS. An Agilent 6890 Gas Chromatograph,

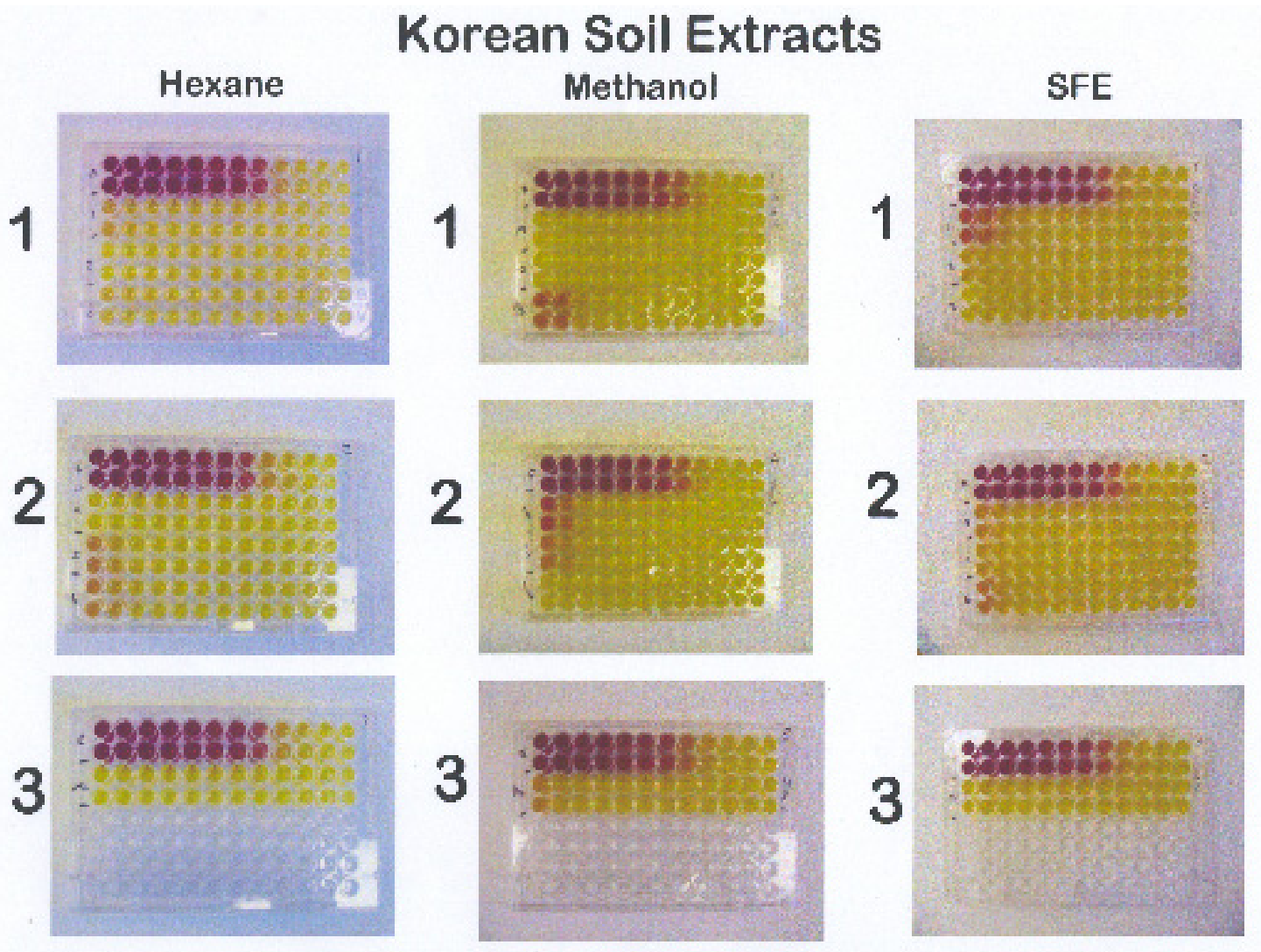

Fig. 1. Micro-plate well YES assay for estrogenetic activity of soil extract. The arrow symbol represent the estrogenetic activity response of each soil-extract fraction. 
a HP-5MS column $(30 \mathrm{~m} \times 0.25 \mathrm{~mm}$ i.d. $\times 0.25 \mu \mathrm{m}$ film thickness) connected with an Agilent 5973 mass selective detector was used. The temperature of column oven was maintained at $150^{\circ} \mathrm{C}$ and raised to $280^{\circ} \mathrm{C}$. Helium was used as the carrier gas at a flow rate of $1.0 \mathrm{ml} / \mathrm{min}$ and the injection volume was $1 \mu l$. The temperatures of injector port and the detector was fixed at $250^{\circ} \mathrm{C}$. The mass spectra and its fragmentation pattern are shown in Fig 4.

\section{RESULTS AND DISCUSSION}

With the growing concern of the presence of endocrine disrupting chemicals in the environment, simple and easy method for the detection and quantification of these chemicals are getting importance for routine monitoring. Solid phase extraction (SPE) and analyzing by liquid chromatography with tandem mass spectrometry (LC-MS-MS) was performed by Kim et $a l^{13)}$ and some other scientists which need long time to extract the molecules. Tashiro et $a l^{21)}$ used SPE followed by fractionation by size exclusion chromatography (SEC) and detection by LC-MS-MS which needed even more time and solvent uses. Our study was to detect the natural estrogenic hormone $17 \beta$-estradiol in the soil samples treated with animal manure by comparing solvent extraction and supercritical fluid extraction (SFE) methods using recombinant yeast estrogenicity (YES) assay. In solvent extraction method, hexane and methanol were used as the extracting solvents whereas supercritical $\mathrm{CO}_{2}$ modified with $10 \%$ methanol were used in the SFE procedure.

The extraction of $17 \beta$-estradiol in soil samples was evaluated by its estrogenic activity using recombinant yeast assays (YES) which has widely been utilized to screen estrogenic activity in various environmental samples due to its physiological simplicity, easy handling and low costs. ${ }^{21-24)}$ Estrogenic activities of hexane and methanol extracts from solvent extraction method were compared with the extracts from SFE procedure in parallel. The color developments in the microtitre plate by the presence of estrogenic compound $(17 \beta$ -estradiol) in hexane, methanol and SFE extracts in compare to that by the standard compound are shown in Fig. 1 and the dose-response curves are shown in Fig. 2 and 3.

The dose-response curves for hexane extracts after $48 \mathrm{~h}$ incubation showed no response but after $72 \mathrm{~h}$ soil samples H-1, H-5 and H-6 showed little estrogenic activity compared to the result from other two extracts conducted producing a negligible value of $\mathrm{EC}_{50}$ (Graph not shown). On the other hand, methanol extracts of samples M-3 and M-4 showed highest activity after $72 \mathrm{~h}$ incubation which gave similar $\mathrm{EC}_{50}$ to that produced by the standard $17 \beta$-estradiol $\left(\mathrm{EC}_{50}\right.$ was 0.0923 for the standard and 0.1154 for M-3 whereas 0.0999 for standard and 0.7828 for M-4; Fig. 3) at approximately 0.8 dilution factor. This was also visualized by the intense color producing in the corresponding wells of the microtitre plates (Fig 1). Dose-response curve of samples M-4 after $48 \mathrm{~h}$ also showed little activity with higher $\mathrm{EC}_{50}$ values $(0.416$ for standard and 0.633 for M-4; Fig. 2) represented the lower production of $\beta$-galactosidase within this time period. Sample-3 was collected from an industrial area which effluents are coming directly to the soils

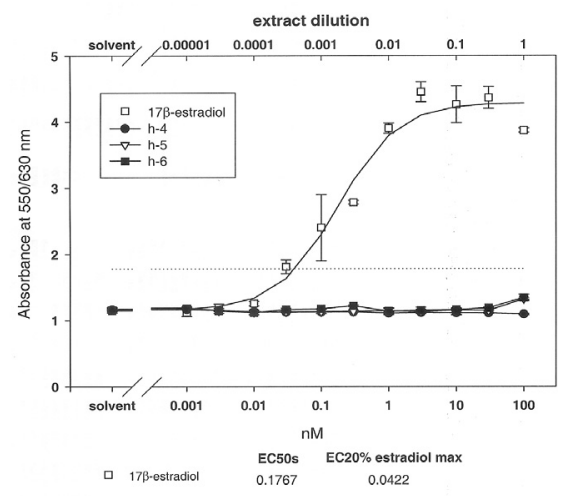

(A)

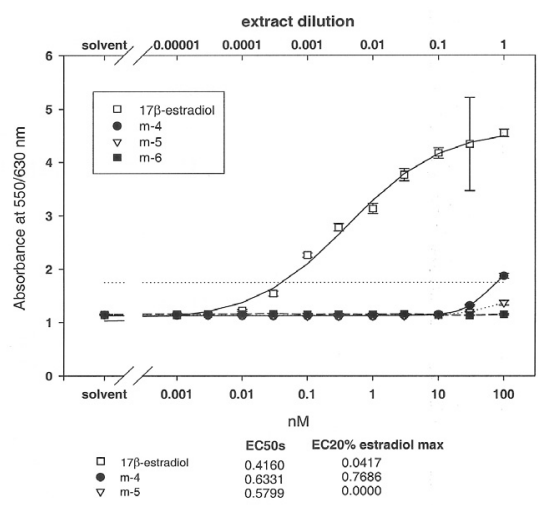

(B)

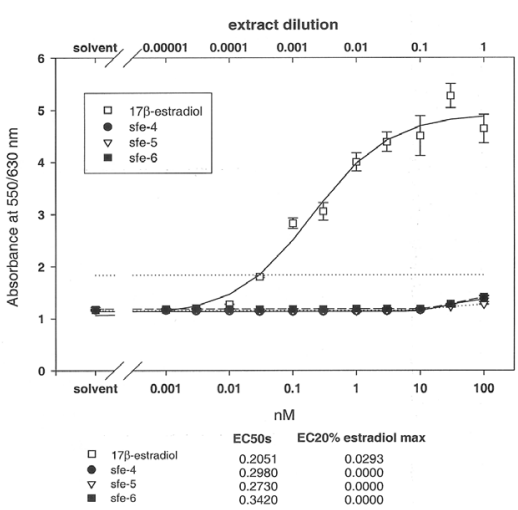

(C)

Fig. 2. Estrogenetic activity of soil extracts obtained by hexane (A), methanol (B) and SFE (C) extraction after 48 hours incubation. Values are means of triplicate measurements. 

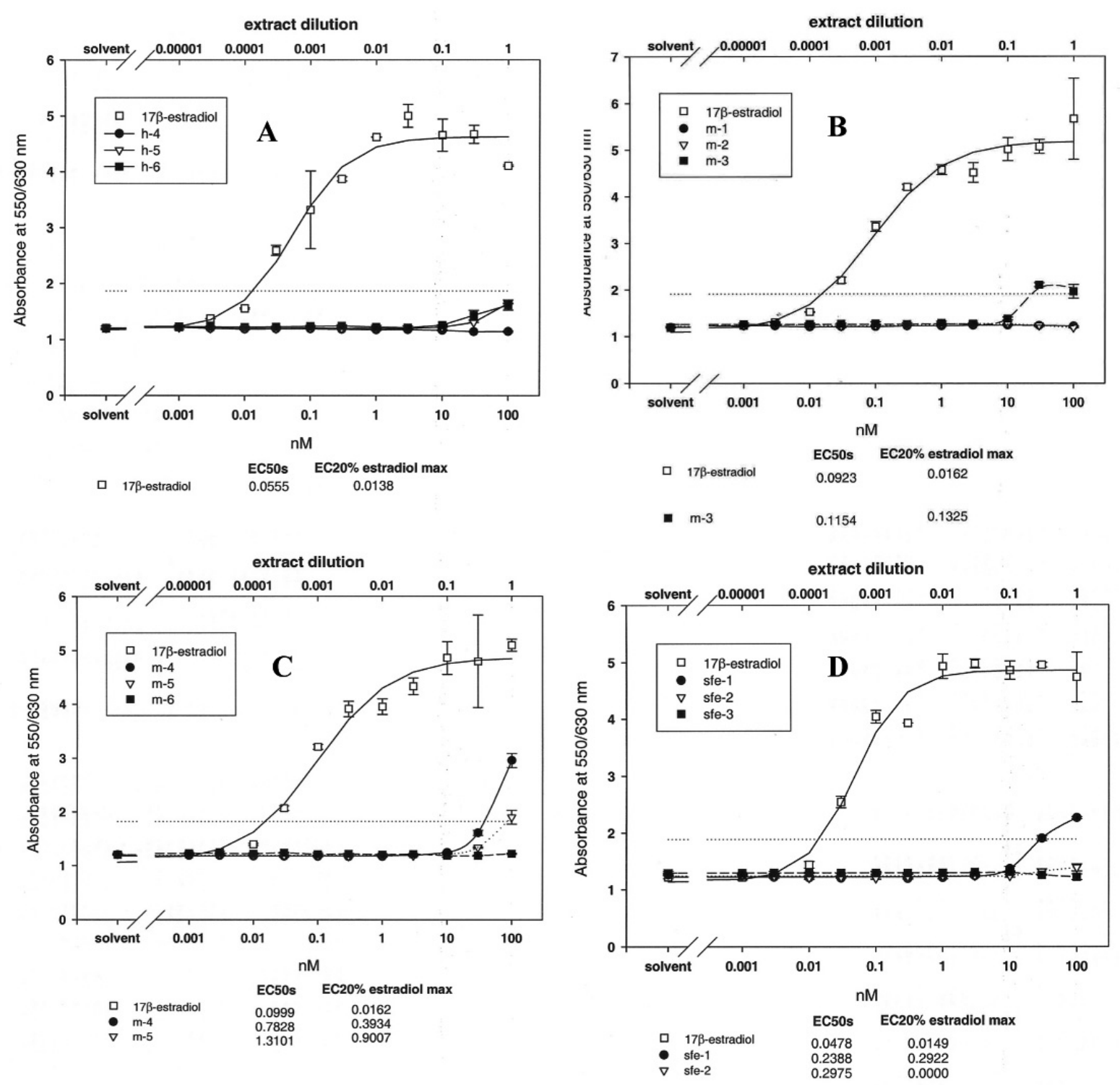

Fig. 3. Estrogenetic activity of soil extracts obtained by hexane (A), methanol (B) and (C) and SFE (D) extraction after 72 hours incubation. Values are means of triplicate measurements.

around making a possible contamination with toxic organic chemicals including endocrine disrupting materials. ${ }^{25)}$ Sample-4 was also collected from the agricultural land around the animal house of Chonnam National University where soils are likely to receive animal manure which is a possible source of organic toxic chemicals. ${ }^{26)}$

In case of supercritical fluid extraction (SFE) method, samples SFE-4 and SFE-5 showed some activities compare to the standard after $48 \mathrm{~h}$ incubation $\left(\mathrm{EC}_{50}\right.$ $=0.205$ for standard and 0.298 for SFE- 4 and 0.2730 for SFE-5) but the color development in the microtitre plate was not that intense compare to the color developed by M-3 and M-4. After $72 \mathrm{~h}$ incubation, the soil sample SFE-1 produced similar color development to that of M-4 and M-3 in the microtitre plate (Fig. 1) and SFE-4, SFE-5 and SFE-6 showed little activity with higher $\mathrm{EC}_{50}$ values compare to the standard $\left(E_{50}=0.062\right.$ for standard and 0.326 for SFE-4, 0.3172 for SFE-5 and 0.3417 for SFE-6; graph not shown). Sample-7 did not show any activity in any of the methods examined. The differences in activities between samples extracted by methanol and SFE are not completely clear, but our findings showed that best activity was observed by the methanol extracts of some soil samples. This might 
be due the polar nature of estradiol.

In supercritical fluid extraction (SFE), pressurized carbon dioxide replaces the organic solvents typically employed in classical extraction. Supercritical fluids diffuse through solids like gases, but dissolve analytes like liquids, so the extraction rate is enhanced and less thermal degradation occurs. ${ }^{27,28)}$ Keeping this view in mind the present study was carried out using a non-polar (hexane), polar (methanol) solvents and a solvent-free SFE techniques. The SFE method for the extraction of $17 \beta$-estradiol did not show better extraction capacity compare to methanol extraction. The process might be check further with other polar compounds in order to make a clear conclusion. The confirmation of the presence of $17 \beta$-estradiol in the soil extracts was carried out by matching the retention time of the peak obtained from the standard reference compound in GC-MS. Mass spectra are shown on Fig. 4.

\section{CONCLUSION}

The extraction of $17 \beta$-estradiol from environmental soil samples was examined using the combination of recombinant yeast estrogenicity (YES) assay and solvent extraction. The utility of super-critical fluid extraction (SFE) method as a simple alternative extraction procedure for $17 \beta$-estradiol was also examined. Methanol extraction method was found to be the most potential one which showed good activity in the YES assay. The presence of $17 \beta$-estradiol in the soil samples analyzed was confirmed by GC-MS. The extraction of estrogenic compounds in soil samples by SFE method did not show any better capacity compare to methanol

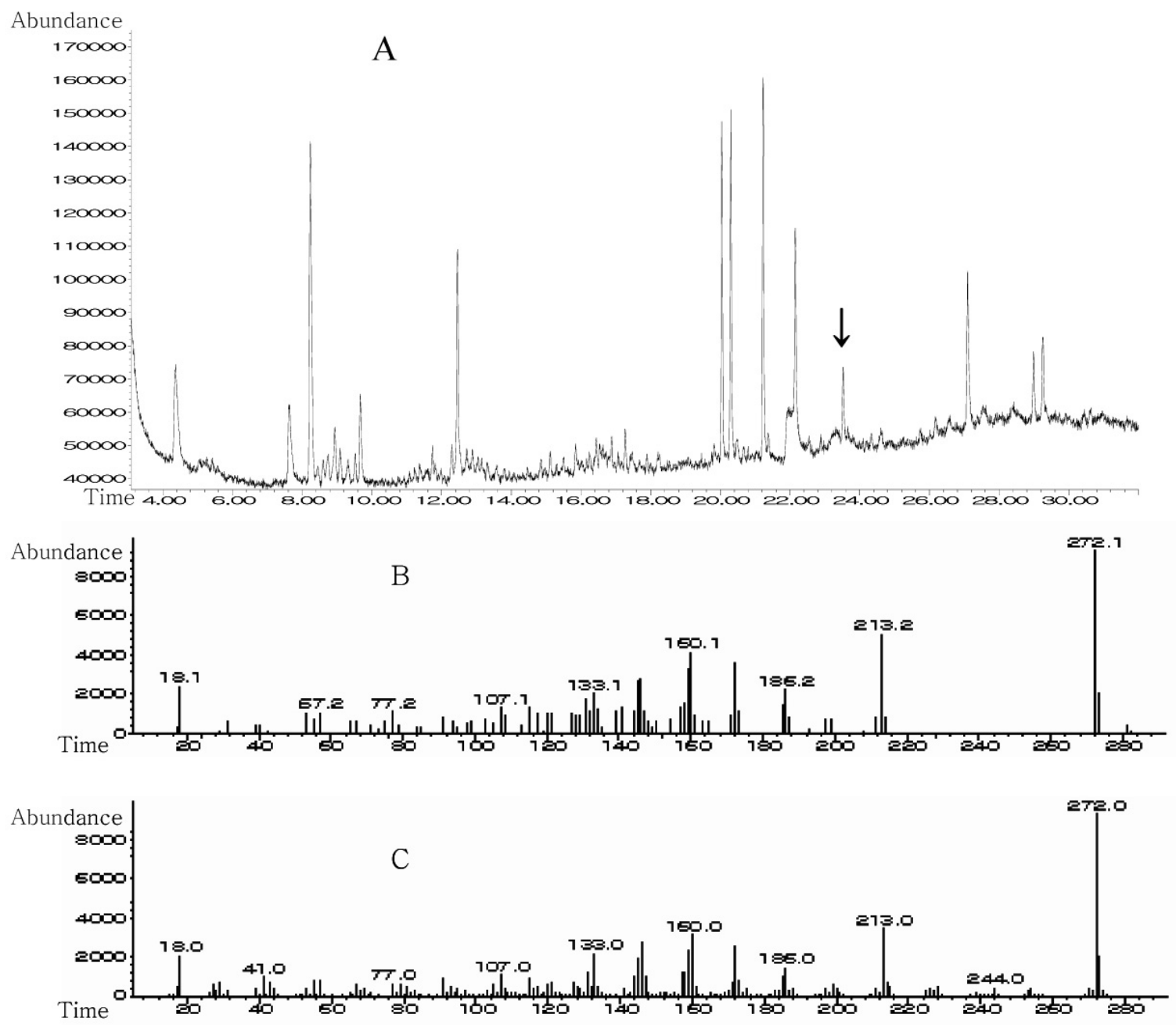

Fig. 4. Typical TIC of $17 \beta$-estradiol in sample (A), fragmentation pattern (B) and mass spectrum from library (C). 
extraction employed under conditions described in this paper. Further investigation may be needed to make a clear conclusion.

\section{ACKNOWLEDGEMENT}

This study was supported from Korea Science \& Engineering Foundation to carry out Research Abroad Program (grant No. F03-2003-000-00056-0) in 2003.

\section{REFERENCES}

1. IUPAC Technical report on "Endocrine Disruptors in the Environment" (2003), Pure Appl. Chem., 75, 631-681.

2. Feldman, D., Tökés, L. G., Stathis P. A., Miller, S. C., Kurz, W. and Harvey, D. (1984) Identification of $17 \beta$ -estradiol as the estrogenic substance in Saccharomyces cerevisiae. Proc. Natl. Acad. Sci. 81, 4722-4726.

3. Colucci, M. S., Bork, H. and Topp, E. (2001) Persistence of estrogenic hormones in agricultural solids: I. $17 \beta$-estradiol and estrone. J. Environ. Qual. 30, 2070-2076.

4. Peterson, E. W., Davis, R. K. and Orndorff, H. A. (2000) $17 \beta$-estradiol as an indicator of animal waste contamination in mantled karst aquifers. $J$. Environ. Qual. 29, 826-834.

5. Belford, A. C., Horst, A. V., Vethaak, A. D., Schäfer, A. J., Rijs, G. B. J., Wegener, J. and Cofino, W. P. (1999) Analysis and occurrence of estrogenic hormones and their glucuronides in surface water and waste water in The Netherlands. Sci. Total Environ. 225, 101-108.

6. Miller, W. R. and Sharpe, R. M. (1998) Environmental oestrogens and human reproductive cancers. Endocrinerelated Cancer 5, 69-96.

7. Colucci, M. S. and Topp, E. (2001) Persistence of estrogenic hormones in agricultural solids: II. $17 a$ -Ethynylestradiol. J. Environ. Qual. 30, 2077-2080.

8. Jobling, S., Nolan, M., Tyler, C. R., Brighty, G. and Sumpter, J. P. (1998) Widespread sexual disruption in wild fish Environ. Sci. Technol 32(17), 2498-2506.

9. Purdom, C. E., Hardiman, P. A., Bye, V. J., Eno, N. C., Tyler C. R. and Sumpter J. P. (1994) Estrogenic effects of effluents from sewage treatment works.
Chem. Ecol. 8(4), 275-285.

10. Desbrow, C., Routledge, E. J., Brighty, G. C., Sumpter, J. P. and Waldock, M. (1998) Identification of estrogenic chemicals in STW effluent. 1. Chemical fractionation and in vitro biological screening. Environ. Sci. Technol 32(11), 1549-1558.

11. Aherne, G. W. and Briggs, R. (1989) The relevance of the presence of certain synthetic steroids in the aquatic environment. J. Pharm. Pharmacol. 41(10), 735-736.

12. Shore, L. S., Gurevitz, M. and Shemesh, M. (1993) Estrogen as an environmental pollutant. Bull. Environ. Contam. Toxicol. 51(3), 361-366.

13. Kim, S. D., Cho, J., Kim, I. S., Vanderford, B. J. and Snyder, S. A., (2007) Occurrence and removal of pharmaceuticals and endocrine disruptors in South Korean surface, drinking, and waste waters. Water Res. 41, 1013-1021.

14. Finlay-Moore, O., Hartel, P. G. and Cabrera, M. L. (2000) 17 beta-eatradiol and testosterone in soil and run-off from grasslands amended with broiler litter. J. Environ. Qual. 29(5), 1604-1611.

15. Raman, D. R., Layton, A. C., Moody, L. B., Easter, L. P., Sayler, G. S., Burns, R. T. and Mullen, M. D. (2001) Degradation of estrogens in dairy waste solids: Effects of acidification and temperature. Transactions of the ASAE 44(6), 1881-1888.

16. Lee, L. S., Strock, T. J., Sarmah, A. K. and Rao, P. S. C. (2003) Sorption and dissipation of testosterone, estrogens, and their primary transformation products in soils and sediment. Environ. Sci. Technol 37(18), 4098-4105.

17. Yu, Z., Xiao, B., Huang, W. and Peng, P. (2004) Sorption of steroid estrogens to soils and sediments. Environ. Toxicol. Chem. 23(3), 531-539.

18. Lerch, O. and Zinn, P. (2003) Derivatisation and gas chromatography-chemical ionization mass spectrometry of selected synthetic and natural endocrine disruptive chemicals. J. Chromatogr. A. 991(1), 77-97.

19. Topp, E. and Starratt, A. (2000) Rapid mineralization of the endocrine-disrupting chemical 4-nonylphenol in soil. Environ. Toxicol. Chem. 19(2), 313-318.

20. Routledge, E. J., and Sumpter, J. P. (1996) Estrogenic activity of surfactants and some of their degradation 
products assessed using a recombinant yeast screen Environ. Toxicol. Chem. 15(3), 241-248.

21. Tashiro, Y., Takahira, K. and Nakanishi, Y. (2004) Improved application of recombinant yeast assays on environmental samples by size exclusion chromatography. J. Environ. Monit. 6, 546-551.

22. Kawagoshi, Y., Fujita, Y., Kishi, I. and Fukunaga, I. (2003) Estrogenic chemicals and estrogenic activity in leachate from municipal waste landfill determined by yeast two-hybrid assay. J. Environ. Monit. 5, 269-274.

23. Rehmann, K., Schramn, K. W. and Kettrup, A. A. (1999) Applicability of a yeast oestrogen screen-like activities in environmental samples. Chemosphere 34(14), 3303-3312.

24. Nishikawa, J., Saito, K., Goto, J., Dakeyama, F., Matsuo, M. and Nishihara, T. (1999) New screening methods for chemicals with hormonal activities using interaction of nuclear hormone receptor with coactivator. Toxicol. Appli. Pharmacol. 154, 76-83.

25. Timms B. G., Howdeshell, K. L. Barton, L., Bradley, S. Richter, C. A. and. Saal F. S. (2005) Estrogenic chemicals in plastic and oral contraceptives disrupt development of the fetal mouse prostate and urethra. Proceedings of the National Academy of Sciences, USA 102(19), 7014-7019.

26. Hanselman, T. A., Graetz, D. A., Wilkie, A. C., Szabo, N. J. and Diaz, C. S. (2006) Determination of Steroidal Estrogens in Flushed Dairy Manure Wastewater by Gas Chromatography-Mass Spectrometry. J Environ Qual 35, 695-700.

27. King, J. W. (1989) Fundamentals and applications of supercritical fluid extraction in chromatographic science_J Chromatographic Sci. 27, 355-364.

28. King, J. W. (1998) Analytical supercritical fluid techniques and methodology: conceptualization and reduction to practice. J AOAC Internat. 81, 9-17. 